\title{
Nanocomposites Based on Polymer and Hydroxyapatite for Drug Delivery Application
}

\author{
M. Sundar Raj ${ }^{*}$, V. H. Arkin ${ }^{2}$, Adalarasu ${ }^{3}$ and M. Jagannath ${ }^{4}$ \\ 'Asst. Professor, Biomedical Engineering, Bharath University, Chennai - 600 073, India; sundarmbe@gmail.com \\ ${ }^{2} R$ \& D Engineer, URILAB Systems- Diagnostics, New Delhi- 110 081; arkinvh@gmal.com \\ 3Professor, Department of ECE, PSNACET, Dindigul - 624 622; adalbiotech@gmail.com \\ 4Prof \& Head - BME, SMK Fomra Institute of Technology, Chennai - 600 103; jagan.faith@gmail.com
}

\begin{abstract}
This research paper tells about sustained delivery of small molecular drug ciprofloxacin using hydroxyapatite hybrid poly (vinyl alcohol) nanocomposites. Hydroxyapatite - poly (vinyl alcohol) nanocomposites are used as a vehicle to carry drug, protein, implantable materials etc. In situ synthesized hydroxyapatite hybrid poly (vinyl alcohol) matrix was characterized using different characterization techniques like XRD, SEM and FTIR. Small molecular drug ciprofloxacin was loaded into hydroxyapatite hybrid poly (vinyl alcohol) nanocomposites. The morphology of drug free and drug loaded hydroxyapatite concoction poly (vinyl alcohol) nanocomposites is observed using SEM. In-vitro drug release is quantified using UV/VIS spectrophotometer.
\end{abstract}

Keywords: Hydroxyapatite (HAP), Poly (Vinyl Alcohol) (PVA), Ciprofloxacin, Nanocomposites, Sustained Release, Drug Delivery, X-ray Diffraction (XRD), Scanning Electron Microscope (SEM).

\section{Introduction}

Conventional form of drug delivery is not target specific and release of drug to the target site is not sustained. Also conventional drugs cause side effect and alternation in circulating the drug level. Novel drug delivery will give steady and complete drug release by polymer hybrid hydroxyapatite (HAP) that will follow a membrane diffusion controlled release mechanism [1]. In the past decade nanocomposites designing and fabrication form different biodegradable polymer and bioactive materials is an essential step to engineer bone tissue [2]. Mineral phase of bone and teeth has the chemical and structural similarity of bioactive ceramic hydroxyapatite, chemical formula $\mathrm{Ca}_{10}\left(\mathrm{PO}_{4}\right)_{6}(\mathrm{OH})_{2}$ also gained much attention because of its biocompatibility, bioactivity, osteoconductivity and osteoproductivity [3, A. 4]. The $\mathrm{Ca}^{++}$ions in hydroxyapatite (inorganic) hybrid with $-\mathrm{OH}$ group of PVA (organic) will give more mechanical strength and osteoconductivity $[5,6,7]$. Because of large surface to volume ratio, will give the properties of porous structure, bioresorbability and ability to take in drug molecule in the surface $[8,9,10]$. Ciprofloxacin $\mathrm{C}_{17} \mathrm{H}_{18} \mathrm{FN}_{3} \mathrm{O}_{3}$, a small molecular drug (MW 331.3415) is one of the broad spectrum antimicrobial carboxyfluoroquinoline agents which have been demonstrate excellent in vitro activity against both gram-positive and gram-negative bacteria [11, 12, 13, 14, 15]. Staphylococcus aureus, staphylococcus epidermidis, pseudomonas aerrginosa and proteus mirabilis are the few pathogens that cause osteomyelitis which can be treated by ciprofloxacin, since the minimal inhibitory concentration of ciprofloxacin is low as $0.25-2 \mu \mathrm{g} / \mathrm{ml}[16,17]$. Hydroxyapatite hybrid PVA nanocomposites are synthesized using biomimetic approach gives a good microporous size to carry drug with sustained and pulsatile release [18].

In this paper, the adsorption and release behavior of ciprofloxacin (Figure 1) which could interact with

*Corresponding author:

M. Sundar Raj (sundarmbe@gmail.com) 


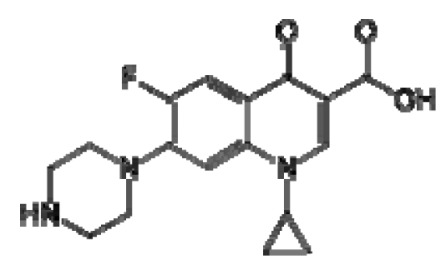

Figure 1.1 Chemical structure of ciprofloxacin.

hydroxyapatite hybrid poly (vinyl alcohol) nanocomposites was studied. Adsorption and release behavior of the drug is performed using in vitro study. Characterization of HAP hybrid PVA nanocomposites is validated using XRD, SEM, and bonding of chemical compounds are analyzed using FTIR. In vitro adsorption and release of the drug is validated using UV- VISIBLE spectrophotometer.

\section{Materials}

$\mathrm{Ca}\left(\mathrm{NO}_{3}\right)_{2} \cdot 4 \mathrm{H}_{2} \mathrm{O}$ (calcium nitrate tertrahydrate) and $\left(\mathrm{NH}_{4}\right)_{2} \mathrm{HPO}_{4}$ (di-ammonium hydrogen phosphate) were purchased from Merck, India. Polyvinyl alcohol was procured from Sigma Aldrich, India. Ciprofloxacin obtained from a pharmacy, deionized water is obtained from Bharath University, Chennai, India.

\section{Synthesis of Polyvinyl Alcohol - Hydroxyapatite Nanocomposites}

Solution of $0.4 \mathrm{M}$ calcium nitrate tetrahydrate $\left(\mathrm{Ca}\left(\mathrm{NO}_{3}\right)_{2}\right.$ $\left..4 \mathrm{H}_{2} \mathrm{O}\right)$ was added in deionized water $(200 \mathrm{ml})$. The $\mathrm{pH}$ of the solution ( $200 \mathrm{ml} 0.4 \mathrm{M}$ calcium nitrate tetrahydrate) should be maintained above 10 . To maintain above $\geq 10 \mathrm{pH}$ add ammonia and water in the ratio 1:2. Prepare $200 \mathrm{ml}$ of $0.5 \%$ poly (vinyl alcohol) (MW 31,000-50,000 Da) solution at temperature $40-50^{\circ} \mathrm{C}$. The prepared $200 \mathrm{ml} 0.4 \mathrm{M}$ calcium nitrate tetrahydrate $\left(\mathrm{Ca}\left(\mathrm{NO}_{3}\right)_{2} \cdot 4 \mathrm{H}_{2} \mathrm{O}\right)$ is added to $0.5 \% 200 \mathrm{ml}$ PVA solution drop wise with stirring. After complete addition, stir both the solution calcium nitrate tetrahydrate $\left(\mathrm{Ca}\left(\mathrm{NO}_{3}\right)_{2} \cdot 4 \mathrm{H}_{2} \mathrm{O}\right)$ and poly (vinyl alcohol) for about $24 \mathrm{hr}$ at $30 \pm 2^{\circ} \mathrm{C}$. $24 \mathrm{hr}$ stirring will allow the binding of $-\mathrm{OH}$ groups of PVA with the $\mathrm{Ca}^{++}$ions. Solution of $0.156 \mathrm{M}$ di-ammonium hydrogen phosphate $\left(\mathrm{NH}_{4}\right)_{2} \mathrm{HPO}_{4}$ was added in $200 \mathrm{ml}$ deionized water. The $\mathrm{pH}$ of the solution (200 $\mathrm{ml} 0.156 \mathrm{M}$ di-ammonium hydrogen phosphate) should be maintained above $\geq 10.5$. To maintain above $\geq 10.5$ add ammonia and water in the ratio 1:1. Completely dissolved $200 \mathrm{ml} 0.156 \mathrm{M}\left(\mathrm{NH}_{4}\right)_{2} \mathrm{HPO}_{4}$ was added to $(\mathrm{Ca}$ $\left.\left(\mathrm{NO}_{3}\right)_{2} \cdot 4 \mathrm{H}_{2} \mathrm{O}\right)$ hybrid PVA solution at about $30 \pm 2^{\circ} \mathrm{C}$ with constant stirring. Complete addition of $\left(\mathrm{NH}_{4}\right)_{2} \mathrm{HPO}_{4}$ to $\left(\mathrm{Ca}\left(\mathrm{NO}_{3}\right)_{2} \cdot 4 \mathrm{H}_{2} \mathrm{O}\right)$ hybrid PVA solution the mixture was washed with deionized water to remove most of the impurities, water soluble salts and to neutralize the $\mathrm{pH}$. After three days of washing the final product is kept at hot air oven for a overnight at about $75-80^{\circ} \mathrm{C}$. The oven dried mixture (Ca $\left.\left(\mathrm{NO}_{3}\right)_{2} \cdot 4 \mathrm{H}_{2} \mathrm{O}\right)$ - PVA - $\left.\left(\mathrm{NH}_{4}\right)_{2} \mathrm{HPO}_{4}\right)$ are characterized by using XRD, SEM and FTIR characterization techniques.

\section{Preparation Methodology for $0.15 \mathrm{M} \mathrm{NaCl}$}

To prepare $0.15 \mathrm{M} \mathrm{NaCl}$ solution,

Mass $=$ required morality $\mathrm{x}$ required volume $\mathrm{x}$ molecular weight of the compound / 1000

$$
\begin{aligned}
& \mathrm{M}=0.15 \times 1000 \times 58.44 / 1000 \\
& \mathrm{M}=8.766 \mathrm{~g} \text { in } 1000 \mathrm{ml} .
\end{aligned}
$$

Take a $1000 \mathrm{ml}$ beaker and mix $8.766 \mathrm{~g}$ of $\mathrm{NaCl}$ into $1000 \mathrm{ml}$ double distilled water. This will give $0.15 \mathrm{M} \mathrm{NaCl}$ solution

\section{Preparation of SBF (Synthetic Body Fluid)}

\subsection{Materials Required}

Sodium chloride $(\mathrm{NaCl})$, sodium bicarbonate $\left(\mathrm{NaHCO}_{3}\right)$, potassium chloride $(\mathrm{KCl})$, disodium hydrogen phosphate dehydrate $\left(\mathrm{Na}_{2} \mathrm{HPO}_{4}\right) 2 \mathrm{H}_{2} \mathrm{O}$, magnesium chloride $\left(\mathrm{MgCl}_{2}\right) 6 \mathrm{H}_{2} \mathrm{O}$, calcium chloride dehydrate $\left(\mathrm{CaCl}_{2}\right) 2 \mathrm{H}_{2} \mathrm{O}$, sodium sulfate $\left(\mathrm{Na}_{2} \mathrm{SO}_{4}\right)$, were from Merck, India and tris (hydroxymethyl) aminomethane (TRIS) $\left(\left(\mathrm{CH}_{2} \mathrm{OH}\right)_{3} \mathrm{CNH}_{2}\right.$ were purchased from HiMedia Laboratories Pvt. Ltd.

\section{Preparation Methodology for SBF (Synthetic Body Fluid)}

For preparing 1 litter of SBF (Synthetic Body Fluid), first add $700 \mathrm{ml}$ deionized water in 1 liter beaker. $40 \mathrm{ml}$ of $1 \mathrm{M}$ $\mathrm{HCl}$ is required to prepare 1 liter of SBF. Add first five reagents according to the order given in the tabular column Table 1 to $700 \mathrm{ml}$ deionized water. Before the addition of sixth reagent add $15 \mathrm{ml}$ of $1 \mathrm{M} \mathrm{HCl}$ to $700 \mathrm{ml}$ deionized water. Sixth, seventh and eight reagent are added subsequently and raise the temperature to $37^{\circ} \mathrm{C}$. The remaining $25 \mathrm{ml} 1 \mathrm{M} \mathrm{HCl}$ solution is added to subsequent titration to 
maintain the $\mathrm{pH}$ of about 7.4 at $37^{\circ} \mathrm{C}$. Add another $300 \mathrm{ml}$ of deionized water to make it to $1000 \mathrm{ml}$ during the titration process. This 1 liter of prepared SBF is stored in $5{ }^{\circ} \mathrm{C}$ for about a month without degradation.

\section{Adsorption of Ciprofloxacin onto Hydroxyapatite - Poly (Vinyl Alcohol) Nanocomposites}

$0.5 \mathrm{~g}$ of hydroxyapatite PVA nanocomposites powder is mixed with $0.10 \%$ ciprofloxacin solution to investigate the adsorption kinetics. The mixed combination of $0.10 \%$ drug (ciprofloxacin) and $0.5 \mathrm{~g}$ of HAP-PVA is agitated at 120 $\mathrm{rpm} / \mathrm{min}$ in a shaker and incubated at $25^{\circ} \mathrm{C}$ for 24 hours. This is done to achieve the adsorption equilibrium. Time intervals, samples were withdrawn from the suspension and centrifuged at $2000 \mathrm{rpm}$ for $10 \mathrm{~min}$ and the supernatant is measured at $277 \mathrm{~nm}$ to find the amount of drug adsorbed by the nanocomposites.

\section{In vitro Drug Release}

To achieve in vitro sustained delivery of drug (ciprofloxacin) is performed using $0.15 \mathrm{M} \mathrm{NaCl}$ as the release media or SBF (Synthetic Body Fluid) as the release media. Here we use $0.15 \mathrm{M} \mathrm{NaCl}$ as the release media, because long period in vitro drug release study is performed in $0.15 \mathrm{M}$ $\mathrm{NaCl}$ medium. $100 \mathrm{mg}$ of CFX-HAP-PVA is loaded into test tube and then $4 \mathrm{ml}$ of $0.15 \mathrm{M} \mathrm{NaCl}$ is added. Then use the shaker to shake the test tube at $25^{\circ} \mathrm{C}$. After certain time intervals, the test tube is centrifuged at $2000 \mathrm{rpm} / \mathrm{min}$ for about $10 \mathrm{~min}$. After centrifugation the $3 \mathrm{ml}$ of supernatant was withdrawn for the validation by U-V VISIBLE spectrophotometer, wavelength of $277 \mathrm{~nm}$ to find the amount of ciprofloxacin (CFX) released. Every $3 \mathrm{ml}$ of withdrawal of supernatant, add new $3 \mathrm{ml}$ of $0.15 \mathrm{M} \mathrm{NaCl}$ fresh release media.

\section{Results and Discussion}

\subsection{XRD Studies}

In Figure 1.2, a broad diffraction peak at 2 theta value shows the conformation of HAP-PVA composites. The diffraction peak analysis was carried out using Debye Sehere's equation: Average crystallite size $(\mathrm{Xs})=0.9 \lambda / \mathrm{FWHM} \cos \theta$, where 0.9 is the constant related with crystalline shape, $\lambda$ is the wave length of the radiation, FWHM (Full width half maximum) peak width in radians at half of the intensity maximum. By calculating different peaks of (002), (211), and (310), the average crystalline size is about $30-34 \mathrm{~nm}$.

\subsection{SEM and EDX Studies}

Figure 1.3 shows the SEM (Scanning electron microscope) image of oven dried hydroxyapatite hybrid poly (vinyl alcohol). The image shows a thick film like structure,

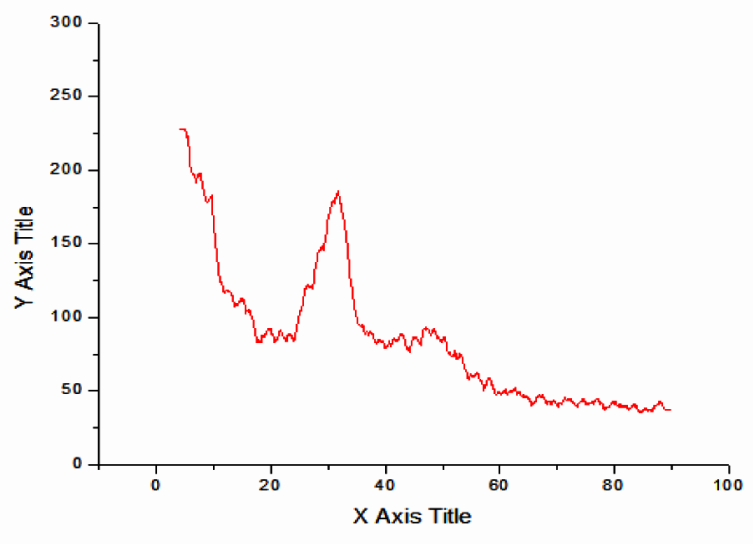

Figure 1.2 XRD of oven dried PVA-HAP composite.

Table 1. The composition of the reagent required to prepare SBF

\begin{tabular}{llc}
\hline Order & Reagent & Amount (gpl) \\
\hline 1. & Sodium chloride $(\mathrm{NaCl})$, & $6.546 \mathrm{~g}$ \\
2. & Sodium bicarbonate $(\mathrm{NaHCO})$, & $2.268 \mathrm{~g}$ \\
3. & Potassium chloride $(\mathrm{KCl})$ & $0.373 \mathrm{~g}$ \\
4. & Disodium hydrogen phosphate dehydrate $\left(\mathrm{Na}_{2} \mathrm{HPO}_{4}\right) 2 \mathrm{H}_{2} \mathrm{O}$ & $0.178 \mathrm{~g}$ \\
5. & magnesium chloride $\left(\mathrm{MgCl}_{2}\right) 6 \mathrm{H}_{2} \mathrm{O}$ & $0.305 \mathrm{~g}$ \\
6. & Calcium chloride dehydrate $\left(\mathrm{CaCl}_{2}\right) 2 \mathrm{H}_{2} \mathrm{O}$ & $0.368 \mathrm{~g}$ \\
7. & Sodium sulfate $\left(\mathrm{Na}_{2} \mathrm{SO}_{4}\right)$, & $0.071 \mathrm{~g}$ \\
8. & Tris $($ hydroxymethyl $)$ aminomethane $\left(\mathrm{CH}_{2} \mathrm{OH}\right)_{3} \mathrm{CNH}_{2}$ & $6.057 \mathrm{~g}$ \\
\hline
\end{tabular}


exhibiting particle size of about (100-200 nm) in polymeric matrix.

\subsection{EDX Analysis}

In the given EDX (Energy dispersive X-ray spectroscopy) Figure 1.4 shows the presence of $\mathrm{Ca}$ and $\mathrm{P}$ in the precipitated PVA-HAP composite. The given HAP-PVA composite

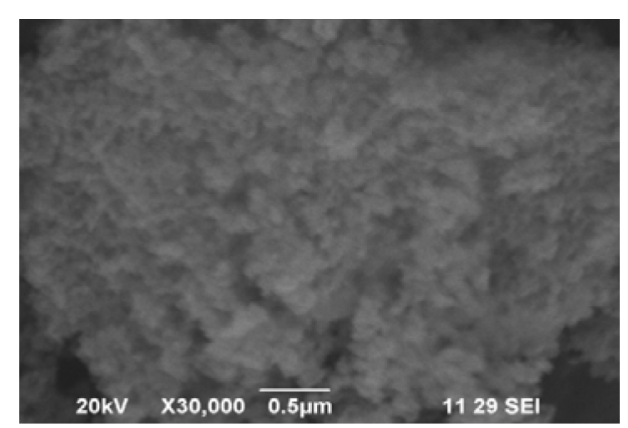

Figure 1.3 SEM image of oven dried PVA-HAP composite. gives the stochiometric ratio of about $\mathrm{Ca}: \mathrm{P} \pm 1.62$ shows in the elemental analysis.

\subsection{SEM Image with Microsphere}

Figure 1.5 (a), (b), shows the SEM studies of the oven-dried HAP-PVA composite powder that confirmed with microspheres having diameter of about the range of 1-2 $\mu \mathrm{m}$.

\subsection{FTIR Studies}

Figure 1.6 reveals the FTIR (Fourier transform infrared spectroscopy) spectra of oven dried hydroxyapatite hybrid poly (vinyl alcohol). The spectra shows the absorbance bands at $3415.93 \mathrm{~cm}^{-1}$ correspond to the presence of hydroxyl groups in the system. Absorbance bands at 1647.21 and $1382.96 \mathrm{~cm}^{-1}$ reveals the presence of $\mathrm{C}=\mathrm{O}$ and $\mathrm{CH}_{2}$ asymmetric bending and bands at 1099.43 and $565.14 \mathrm{~cm}^{-1}$ shows the presence of phosphate group in the hydroxyapatite hybrid PVA nanocomposites system.

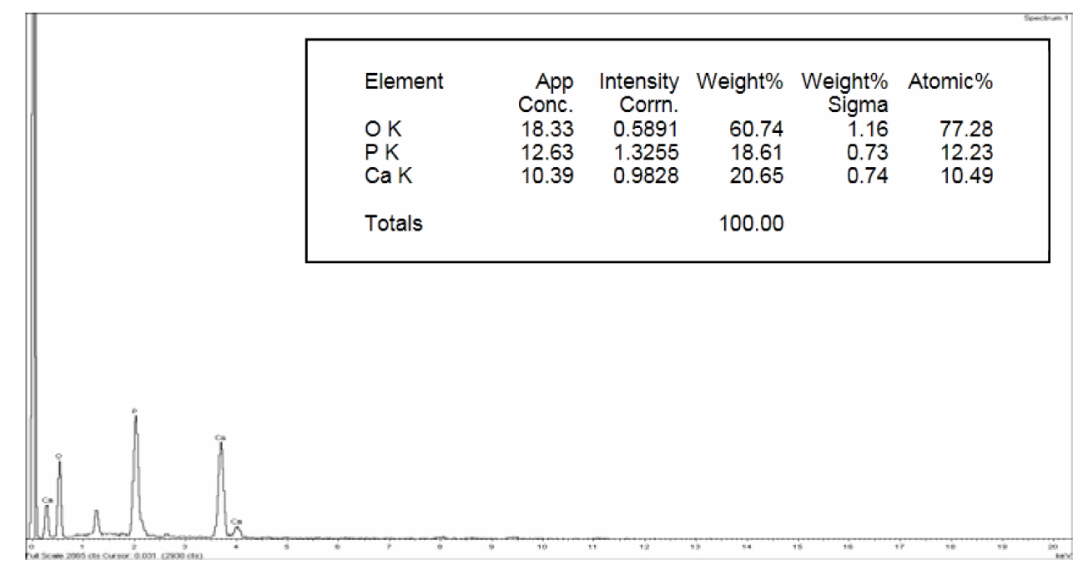

Figure 1.4 Shows the EDX of as precipitated PVA-HAP composite.

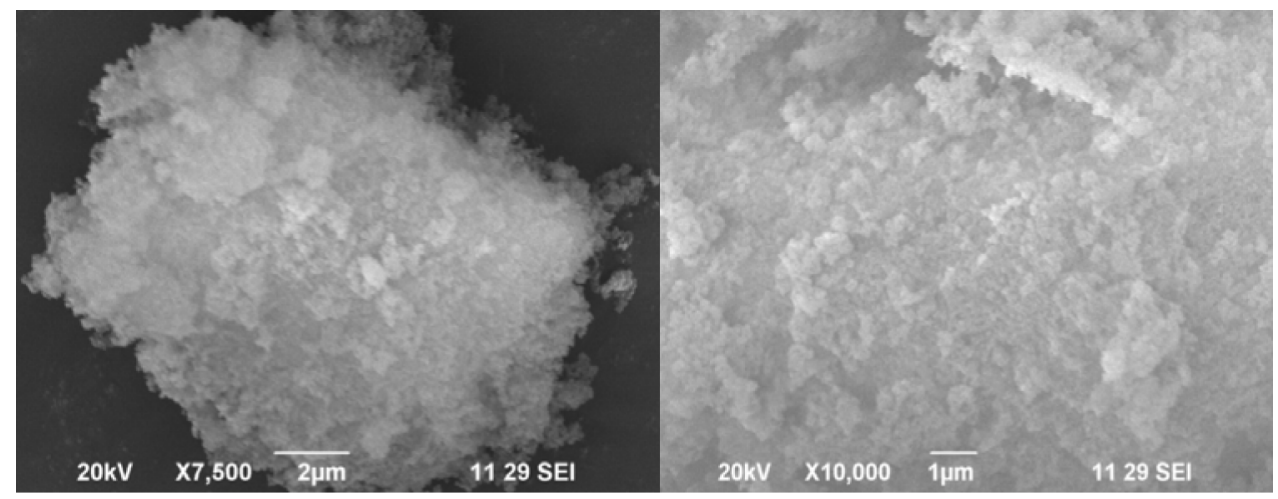

Figure 1.5 (a), (b), SEM images shows the HAP-PVA microsphere. 


\subsection{In vitro Ciprofloxacin Release}

Carrying and delivery of active drugs to the infection site was frequently extended to resorbable and even to soluble biomedical polymer. HAP and PVA has the ability to absorb and release the drug ciprofloxacin also has the biocompatible and nanocomposites which gives more advantage [19]. The given Figure 1.7 shows the release kinetics of ciprofloxacin from HAP-PVA oven dried nanocomposites using $0.15 \mathrm{M} \mathrm{NaCl}$. Normal hydroxyapatite will show a burst release in the initial stage. Coating of HAP by PVA shows the sustained release of about 70\% drug in 7days and 12 hours. This shows that bioceramic material hydroxyapatite hybrid with biopolymer PVA nanocomposites help to adsorb small molecular drug and gives shows a sustained release in in-vitro analysis.

\section{Conclusion}

Novel drug loaded hydroxyapatite (HAP) coated poly (vinyl alcohol) (PVA) microsphere have been synthesized by biomimetic method and adsorption - release properties of drug ciprofloxacin was investigated. Interaction of drug between ciprofloxacin and hydroxyapatite hybrid poly (vinyl alcohol) surface and the release profile obtained from UV analyses. Further this work can be carried out by in vitro anti bacterial testing and coating of CFX-HAP-PVA in to materials like titanium alloy for controlled and targeted drug release by in vivo study can be done.

\section{Acknowledgement}

This research is supported by Crystal Research Center and Pharmaceutical Chemistry, Bharath University, Chennai, India.

\section{References}

1. Wang X, Hui A et al. (2010). Towards sustained delivery of small molecular drugs using hydroxyapatite microsphere as the vehicle, Advance Power Technology, vol 21(3), 268-272.

2. Wahl D A, and Czernuszka J T (2006). Collagen hydroxyapatite composites for hard tissue repair, European Cells and Materials, vol 11, 43-56.

3. Degirmembasi N, Kalyon D M et al. (2006). Biocomposites of nanohdyroxyaaptite will collegen, and poly (vinyl alcohol), Colloids and Surfaces B: Biointerfaces, vol 48(1), 42-49.

4. Asron A S, Henning S et al. (2010). Poly vinyl alcohol collegen hydroxyapatite biocomposites, nano fibrous scaffold: mimicking the key feature of natural bone at the nanoscale level, Polymer, vol 51(4), 868-876.

5. Taguchi T, Kishida A et al. (1998). Hydroxyapatite formation on/in poly(vinyl alcohol) hydrogel matrices using a novel alternate soaking process, Chemistry Letters, vol 27, No. 8, 711-712.

6. Pan Y S, Xiong D S et al. (2007). Friction characteristics of poly (vinyl alcohol) hydrogel as an articular cartilage biomaterial, Key Engineering Materials, vol 330-332, 1297-1300.

7. Noguchi T, Yamamuro T et al. (1991). Poly (vinyl alcohol) hydrogel as an artificial articular cartilage: evaluation of

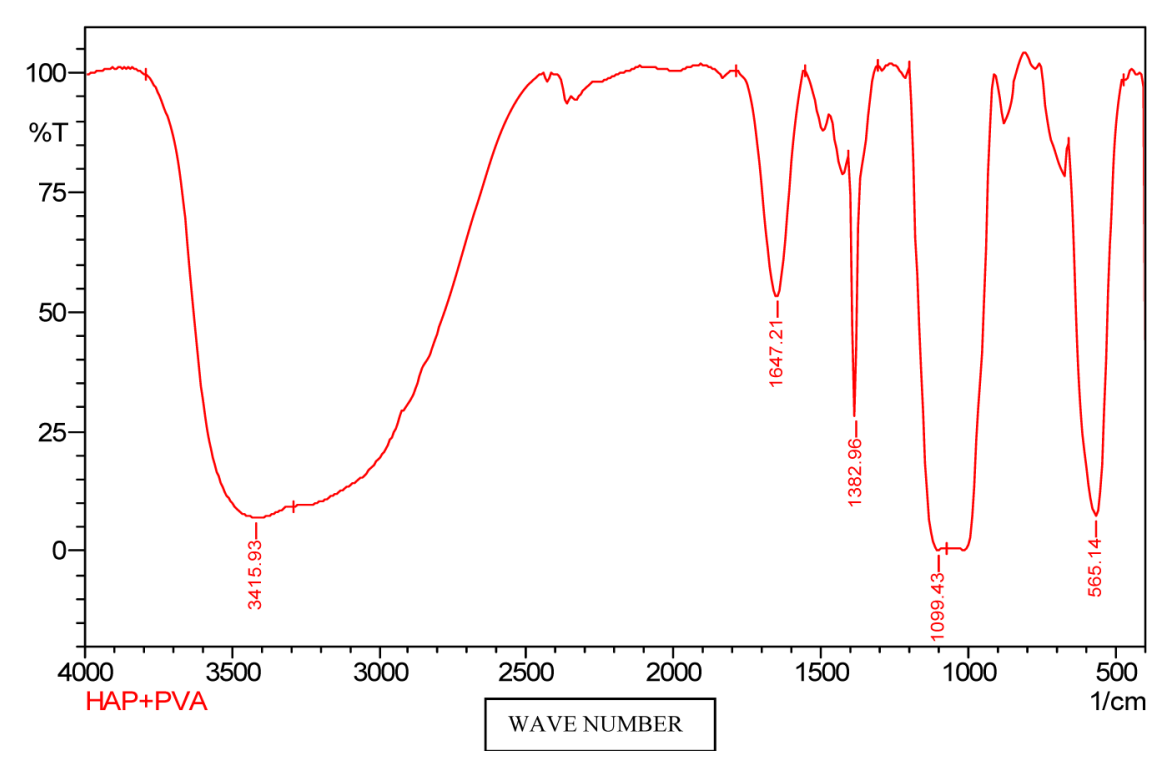

Figure 1.6 FTIR spectra of oven-dried HAP-PVA particle. 


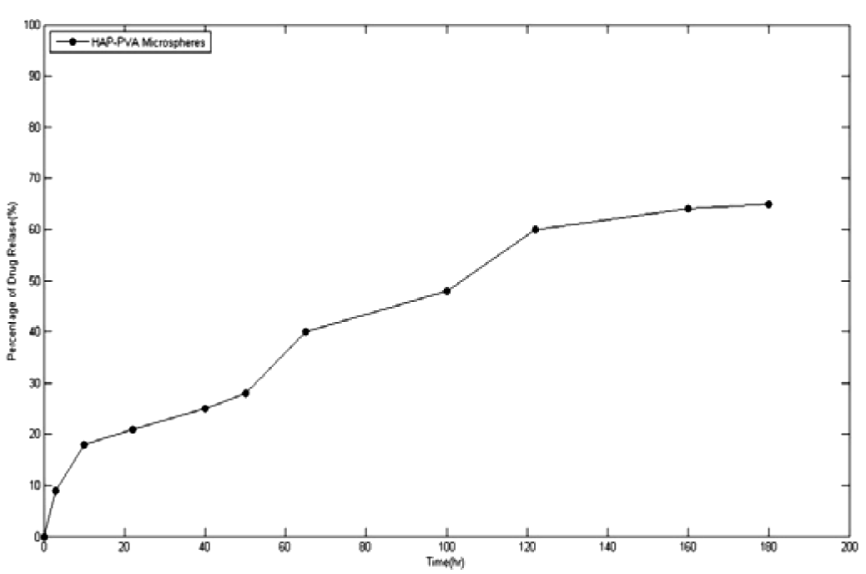

Figure 1.7 In vitro drug release of CFX adsorbed HAP-PVA

biocompatibility, Journal of Applied Biomaterials, vol 2(2), 101-107.

8. Paul W, and Sharma C P (2003). Ceramic drug delivery: a perspective, Journal of Biomaterials Application, vol 17(4), 253.

9. Paul W, and Sharma C P (2006). Nanoceramic materials: Biomedical applications, American Journal of Biochemistry \& Biotechnology, vol 2, 41-48.

10. Barroug A, and Glimche M (2002). Hydroxyapatite crystals as a local delivery system for cisplatin: adsorption and release of cisplatin in vitro. Journal of orthopaedics, vol 20(2), 274-280.

11. Chow A W, Hall C B et al. (1992). General guidelines for the evaluation of new anti-infective drugs for the treatment of respiratory tract infections, Clinical Infectious Diseases, vol 15(Supplement 1), S62-S88.

12. Mylotte J M, Ksiazek S et al. (1994). Bentley Rational approach to the antibiotic treatment of pneumonia in elderly, Drug \& Aging, vol 4(1), 21-33.

13. Cunha B A (1995). The antibiotic treatment of communityacquired, athipical, and nosocomial pneumonias, The Medical clinics of North America, vol 79(3), 581-597.

14. Vogel F (1995). A guide to the treatment of lower respiratory tract infections, Drugs, vol 50(1), 62-72.

15. Ortqvist A (1995). Antibiotic treatment of communityacquired pneumonia in clinical practice: a European perspective, Journal of Antimicrobial Chemotherapy, vol 35(1), 205-212.

16. Lambert H P, and O'Grady F W (1992). Antibiotic and Chemotherapy, 6th Edn., Churchill Livingstone, Edinburgh, 245-262.

17. Armstrong E P, Elsberry V A (1997). Bone and joint infections, Dipiro J T, Talbert R L, Yee G C, Matzke G R, Wells B G, Posey L M (Eds.), Pharmacotherapy. A Pathophysiologic Approach, 3rd Edn, Appleton \& Lange, Stamford, 2221-2235.

18. Gupta S, Nayar S et al. (2008). Effect of particle morphology on drug release from poly (vinyl alcohol)- hydroxyapatite nanocomposites, Kapecele J. Soluble biomedical polymers, polim med vol 7(3), 191-221.

19. Shiffman ML, and Keith FB(1990). Pathogenesis of ceftriaxoneassociated biliary sludge, In vitro studies of calcium ceftriaxone binding and solubility, Gastroenterology, vol 99(6), 1772-1778. 